\title{
Upregulation of the Hyperpolarization-Activated Cation Current after Chronic Compression of the Dorsal Root Ganglion
}

\author{
Hang Yao, ${ }^{1}$ David F. Donnelly, ${ }^{2}$ Chao Ma, ${ }^{1}$ and Robert H. LaMotte ${ }^{1}$ \\ Departments of ${ }^{1}$ Anesthesiology and ${ }^{2}$ Pediatrics, Yale University School of Medicine, New Haven, Connecticut 06510
}

\begin{abstract}
A chronic compression of the DRG (CCD) produces cutaneous hyperalgesia and an enhanced excitability of neuronal somata in the compressed ganglion. The hyperpolarization-activated current $\left(I_{h}\right)$, present in the somata and axons of DRG neurons, acts to induce a depolarization after a hyperpolarizing event and, if upregulated after CCD, may contribute to enhanced neuronal excitability. Whole-cell patch-clamp recordings were obtained from acutely dissociated, retrogradely labeled, cutaneous, adult rat DRG neurons of medium size. Neurons were dissociated from $\mathrm{L}_{4}$ and $\mathrm{L}_{5}$ control DRGs or DRGs that had each been compressed for 5-7 d by L-shaped rods inserted into the intervertebral foramina. $I_{\mathrm{h}}$, consisting of a slowly activating inward current during a step hyperpolarization, was recorded from every labeled, medium-sized neuron and was blocked by $1 \mathrm{~mm}$ cesium or $15 \mu \mathrm{M}$ ZD7288. Compared with control, CCD increased the current density and rate of activation significantly without changing its reversal potential, voltage dependence of activation, or rate of deactivation. Because $I_{\mathrm{h}}$ activation provides a depolarizing current to the neuron, thus enhancing neuronal excitability, our results are consistent with the hypothesis that $I_{\mathrm{h}}$ contributes to hyperalgesia after CCD-induced nerve injury.
\end{abstract}

Key words: hyperpolarization-activated current; $I_{\mathrm{h}}$; ion channels; dorsal root ganglion compression; neuropathic pain; rats

\section{Introduction}

A chronic compression of the $\mathrm{L}_{4}$ and $\mathrm{L}_{5}$ dorsal root ganglia (CCD) produces cutaneous hyperalgesia and tactile allodynia on the ipsilateral foot in the rat (Song et al., 1999). The cell bodies (somata) of the dorsal root ganglia (DRGs) exhibit signs of hyperexcitability, such as a lower rheobase, and an increased incidence of spontaneous activity (Hu and Xing, 1998; Song et al., 1999; Zhang et al., 1999). These alterations in the membrane properties of DRG somata might contribute to the cutaneous hyperalgesia and allodynia after CCD. However, the underlying ionic mechanisms of the increased somal excitability after CCD are not well understood.

One type of current that might contribute to the presence and frequency of spontaneous activity after CCD is $I_{\mathrm{h}}$. $I_{\mathrm{h}}$ current, carried by hyperpolarization-activated, cyclic nucleotide-gated channels (HCN), is a nonselective cation current activated by a membrane hyperpolarization occurring, for example, at the end of an action potential. The activation of $I_{\mathrm{h}}$ produces an inward current that slowly depolarizes the membrane (Pape, 1996). As a pacemaker current, $I_{\mathrm{h}}$ contributes to the rate of spontaneous rhythmic oscillations in the heart and in the brain (DiFrancesco, 1993; Luthi and McCormick, 1998). $I_{\mathrm{h}}$ is also present in DRG neurons (Mayer and Westbrook, 1983; Scroggs et al., 1994; Villiere and McLachlan, 1996; Yagi and Sumino, 1998; Cardenas et al., 1999) and is implicated in increasing discharge rate to excitatory stimuli by limiting membrane hyperpolarization and facilitating depolarization (Yagi and Sumino, 1998). Stimuli that modulate $I_{\mathrm{h}}$ can alter neuronal excitability. For example, certain

\footnotetext{
Received Aug. 1, 2002; revised Dec. 24, 2002; accepted Dec. 30, 2002.

This work was supported by the National Institutes of Health/National Institute of Neurological Disorders and Stroke Grant NS-14624.

Correspondence should be addressed to Robert H. LaMotte, Department of Anesthesiology, Yale University School of Medicine, 333 Cedar Street, P.0. Box 208051, New Haven, CT 06520-8051. E-mail: robert.lamotte@yale.edu. Copyright $\odot 2003$ Society for Neuroscience $\quad 0270-6474 / 03 / 232069-06 \$ 15.00 / 0$
}

inflammatory mediators, such as serotonin, increase intracellular cAMP, which, in turn, increases $I_{\mathrm{h}}$ current by binding to the $\mathrm{HCN}$ channel and shifting the voltage dependence of activation (Raes et al., 1997; Cardenas et al., 1999).

In the present study, we examined the biophysical properties of $I_{\mathrm{h}}$ current in cutaneous, medium-sized somata acutely dissociated from DRGs of CCD and unoperated control rats. Our hypothesis was that CCD induces an increase in the magnitude and/or an alteration in the kinetics of activation-deactivation of $I_{\mathrm{h}}$.

\section{Materials and Methods}

Labeling of cutaneous neurons and CCD surgery. Twenty-two female Sprague Dawley rats (140-160 gm) were anesthetized with pentobarbital (40 mg/kg, i.p.). Cutaneous afferent neurons were retrogradely labeled by injecting Fluorogold solution in saline $(1 \%, 0.05 \mathrm{ml}$; Molecular Probes, Eugene, OR) subcutaneously into the right lateral plantar region (Oyelese and Kocsis, 1996). To determine whether there was dye leakage from the subcutaneous space to the neighboring muscle, True Blue (1.5\%, $0.05 \mathrm{ml}$; Molecular Probes) was injected into the exposed gastrocnemius and soleus muscles (Liu et al., 2002). Immediately after the injections, in CCD rats $(n=11)$, the ipsilateral, right transverse process and intervertebral foramina of $\mathrm{L}_{4}$ and $\mathrm{L}_{5}$ were exposed as described previously (Hu and Xing, 1998; Song et al., 1999). A stainless steel L-shaped rod $(0.63 \mathrm{~mm}$ in diameter and $4 \mathrm{~mm}$ in length) was inserted into each foramen, one at $\mathrm{L}_{4}$ and the other at the $\mathrm{L}_{5}$ ganglion. The remaining 11 rats received no additional surgery and were used as controls.

Cell preparation. Five to $7 \mathrm{~d}$ after surgery, the rats were deeply anesthetized with pentobarbital ( $40 \mathrm{mg} / \mathrm{kg}$, i.p.), and the $\mathrm{L}_{4}$ and $\mathrm{L}_{5}$ lumbar $\mathrm{DRGs}$ were exposed. In CCD rats, the correct placement of each implanted rod was confirmed. Only one DRG was discarded because of incorrect placement of the rod. DRGs were removed from control or CCD rats and placed in complete saline solution (CSS) for cleaning and mincing. The CSS contained the following (in $\mathrm{mm}$ ): $137 \mathrm{NaCl}, 5.3 \mathrm{KCl}, 1 \mathrm{MgCl}_{2}, 3$ $\mathrm{CaCl}_{2}, 25$ sorbitol, and 10 HEPES. The DRGs were then digested for 15 min with collagenase A $(1 \mathrm{mg} / \mathrm{ml}$; Boehringer Mannheim, Mannheim, Germany) and for another $15 \mathrm{~min}$ with collagenase D (1 mg/ml; Boeh- 
ringer Mannheim) and papain (30 U/ml; Worthington, Lakewood, NJ) in CSS containing $0.5 \mathrm{~mm}$ EDTA and $2 \mu \mathrm{g}$ of cysteine at $37^{\circ} \mathrm{C}$ as described previously (Rizzo et al., 1995). The cells were dissociated by trituration in culture medium containing $1 \mathrm{mg} / \mathrm{ml}$ bovine serum albumin and $1 \mathrm{mg} / \mathrm{ml}$ trypsin inhibitor (Boehringer Mannheim) and plated on glass coverslips coated with polyornithine and laminin. The culture medium contained equal amounts of DMEM (Invitrogen, San Diego, CA) and F-12 (Invitrogen) with $10 \%$ FCS (HyClone, Logan, UT) and 1\% penicillin and streptomycin (Invitrogen). The cells were incubated at $37^{\circ} \mathrm{C}\left(5 \% \mathrm{CO}_{2}\right.$ balance air) for $1 \mathrm{hr}$, after which culture medium without the inhibitor was added.

Electrophysiological recording and drug application. Coverslips were transferred to a recording chamber that was mounted on the stage of an upright microscope (BX50-WI; Olympus Optical, Tokyo, Japan). The chamber was filled with bath solution containing the following (in $\mathrm{mM}$ ): $125 \mathrm{NaCl}, 3 \mathrm{KCl}, 1 \mathrm{CaCl}_{2}, 1 \mathrm{MgCl}_{2}, 10$ HEPES, 10 glucose, 10 TEA-Cl, 3 4-AP, $2 \mathrm{MnCl}_{2}, 1 \mathrm{BaCl}_{2}$, and 0.001-0.005 TTX. The $\mathrm{pH}$ was adjusted to 7.4 with $\mathrm{NaOH}$, and osmolarity was adjusted with sucrose to $290 \mathrm{mOsm}$. Neurons selected for recording were 35-45 $\mu \mathrm{m}$ in diameter and were positive for Fluorogold fluorescence and negative for True Blue fluorescence. Electrodes were fabricated from borosilicate glass (World Precision Instruments, Sarasota, FL) and pulled on a Flaming/Brown micropipette puller (Sutter P-97; Sutter Instrument, Novato, CA). The pipette solution contained the following (in $\mathrm{mM}$ ): $120 \mathrm{~K}$-aspartate, $18 \mathrm{KCl}, 1$ $\mathrm{CaCl}_{2}, 2 \mathrm{MgCl}_{2}, 5$ EGTA, 10 HEPES, $5 \mathrm{Na}_{2}$-ATP, and $0.4 \mathrm{Na}-\mathrm{GTP}$. The $\mathrm{pH}$ was adjusted to 7.2 with $\mathrm{KOH}$, and osmolarity was $295 \mathrm{mOsm}$ (pipette resistance, $1-2 \mathrm{M} \Omega$ ).

Neurons were recorded at room temperature in the whole-cell mode (Multiclamp 700A; Axon Instruments, Union City, CA) using pClamp 8.01 software (Axon Instruments). Data were filtered at $3 \mathrm{kHz}$ and digitized at $20 \mathrm{kHz}$. The voltage drop across the access resistance was compensated at $40-80 \%$, resulting in a voltage error of $<8 \mathrm{mV}$. Cesium and ZD7288 were applied locally through a perfusion pipette $(100 \mu \mathrm{m}$ in diameter) using a drug application system (ALA Scientific Instruments, Long Island, NY). All of the chemicals were purchased from Sigma (St. Louis, MO) unless otherwise indicated.

Data analysis. Data were fit using pClampfit 8.1 (Axon Instruments) and Origin 6.0 (Microcal Software, Northampton, MA). The goodness of fit was determined either by the "model comparison" method in pClampfit 8.1 or the logarithm of the error ratio criterion (Horn, 1987). Data are expressed as mean \pm SD unless otherwise indicated. Tests for statistical differences between means for CCD and control neurons were determined with either Student's $t$ tests or repeated-measures ANOVA (RMANOVA), followed by post hoc pairwise comparisons [Tukey's honestly significant difference (HSD) test]. The criterion for statistical significance was a value of $p<0.05$.

\section{Results}

\section{CCD increases the density of $I_{\mathrm{h}}$ current}

A total of 254 DRG neurons were recorded, 120 from 11 control and 134 from 11 CCD rats. There was no difference in cell size for the two groups. The whole-cell capacitance was $78.7 \pm 3.0 \mathrm{pF}$ $(n=51)$ for control and $74.8 \pm 3.6 \mathrm{pF}(n=34)$ for CCD neurons (Student's $t$ test; $p=0.41$ ). To activate $I_{\mathrm{h}}$, hyperpolarizing potentials of -60 to $-120 \mathrm{mV}$ were delivered in increments of $-10 \mathrm{mV}$ from a holding potential of $-50 \mathrm{mV}$ (Fig. $1 \mathrm{~A}$, inset). Slowly activating, inward currents (Fig. $1 A$, top row) were blocked by the addition of cesium $(1 \mathrm{mM})$ to the bath solution (Fig. $1 A$, middle row), consistent with an $I_{\mathrm{h}}$ current. Cesium blocked $95.5 \pm 2.4 \%$ of the inward current in control neurons $(n=12)$ and $95.9 \pm$ $3.1 \%$ in CCD neurons $(n=12)$. In other experiments, ZD7288 $(15 \mu \mathrm{M})$, a specific $I_{\mathrm{h}}$ channel blocker (BoSmith et al., 1993; Gasparini and DiFrancesco, 1997; Satoh and Yamada, 2000), showed a similar inhibitory effect, blocking $91.0 \pm 5.2 \%$ of the inward current in CCD neurons $(n=12)$ and $96.5 \pm 3.3 \%$ in control neurons $(n=12)$. The inhibition by cesium but not by ZD7288 was reversed during $30 \mathrm{~min}$ of washout (Fig. $1 \mathrm{~A}$, bottom

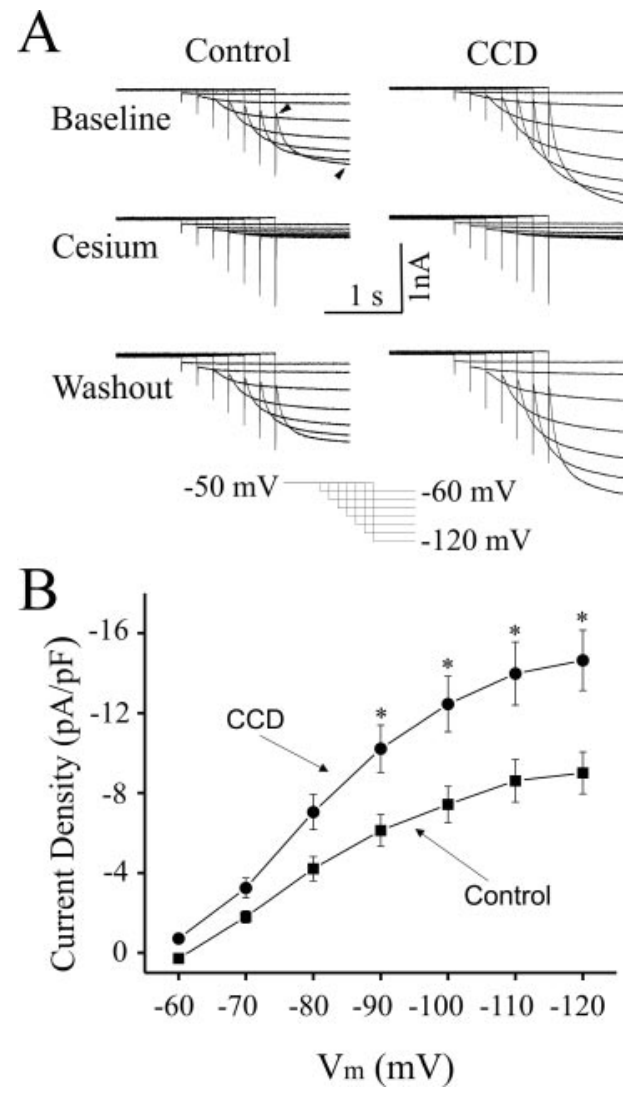

Figure 1. The effects of $C C D$ on the density of $I_{h}$ current. $A$, Current responses evoked by hyperpolarizing voltage steps from a holding potential of $-50 \mathrm{mV}$ in a control (left) and a CCD (right) DRG neuron. The voltage protocol is shown at the bottom. $I_{\mathrm{h}}$ current amplitude was calculated from the difference between the steady-state and the instantaneous currents (i.e., the difference between the two arrows shown as an example at the last trace of the left top traces). In both panels, families of current responses on the top were recorded in the control bath solution. Middle traces, $\mathrm{Cs}^{+}$at $1 \mathrm{~mm}$. Bottom traces, After $2 \mathrm{~min}$ of washout. Voltage protocol is shown as an inset at bottom. $B, I_{\mathrm{h}}$ current density versus membrane potential, $V_{\mathrm{m}}$. Squares and circles represent the data summarized from 34 control and 51 CCD neurons, respectively. Error bars indicate SEM. * Indicates that means at the same membrane voltage are significantly different.

row). The sensitivity of $I_{\mathrm{h}}$ to these inhibitors is consistent with that described previously for $I_{\mathrm{h}}$ (Yagi and Sumino, 1998; Cardenas et al., 1999). The magnitude of $I_{\mathrm{h}}$ current increased with increasing hyperpolarization (Fig. $1 \mathrm{~A}$, top row). At $-60 \mathrm{mV}$, the mean magnitude of $I_{\mathrm{h}}$ was $-22.9 \pm 5.7 \mathrm{pA}$ for control neurons and $-53.6 \pm 10.9 \mathrm{pA}$ for CCD neurons. At $-120 \mathrm{mV}, I_{\mathrm{h}}$ was $-698.6 \pm 85.2 \mathrm{pA}(n=34)$ for control and $-1156.7 \pm 115.1 \mathrm{pA}$ $(n=51)$ for CCD neurons. When normalized to cell capacitance, CCD neurons had a significant increase in $I_{\mathrm{h}}$ current density by 66.6-61.5\% compared with control neurons over the voltage range of -90 to $-120 \mathrm{mV}$ (control, $n=34$; CCD, $n=51$; twoway RMANOVA, $p<0.05$ ) (Fig. $1 B$ ). For example, at $-100 \mathrm{mV}$, the current density was $7.4 \pm 0.9 \mathrm{pA} / \mathrm{pF}$ for control and $12.4 \pm$ $1.3 \mathrm{pA} / \mathrm{pF}$ for CCD neurons, a $67 \%$ increase in the latter group (Fig. $1 B$ ).

\section{CCD increases the conductance but not the reversal potential of $I_{\mathrm{h}}$ current}

The reversal potential and the maximal $I_{\mathrm{h}}$ conductance were measured by first applying a prepulse to $-100 \mathrm{mV}$ to fully activate $I_{\mathrm{h}}$ and then examining the tail currents after repolarization to test potentials from -90 to $-50 \mathrm{mV}$ (Fig. $2 A$, inset). The time point for measure- 
ment of the peak tail current is shown in Figure $2 \mathrm{~A}$ (arrows). For each test voltage, the peak tail current, after subtraction of the estimated leak current, was averaged for 31 control and 31 CCD neurons, and each was fitted with a linear regression equation, as follows: $I_{\text {tail }}=G_{\text {h.max }}\left(V_{\mathrm{m}}-V_{\text {rev }}\right)$, where $I_{\text {tail }}$ is the peak tail current, $V_{\mathrm{m}}$ is the membrane potential of the test pulse, $G_{\mathrm{h} . \max }$ is the maximal conductance, and $V_{\text {rev }}$ is the reversal potential of $I_{\mathrm{h}}$ current (Fig. $2 \mathrm{~B}$ ). This fitting yielded estimates of $G_{\mathrm{h} . \max }, V_{\text {rev }}$ of $0.15 \mathrm{nS} / \mathrm{pF},-21 \mathrm{mV}$ for the control neuron and $0.23 \mathrm{nS} / \mathrm{pF},-23 \mathrm{mV}$ for the CCD neuron. The mean $V_{\text {rev }}$ values of $-21.3 \pm 1.4 \mathrm{mV}(n=31)$ for control neurons and $-22.3 \pm 1.0 \mathrm{mV}(n=31)$ for CCD neurons were not significantly different (Student's $t$ test; $p=0.55$ ). As expected from the data in Figure 1, CCD neurons exhibited a significant increase $(76 \%)$ in maximal $I_{\mathrm{h}}$ conductance, from $0.13 \pm 0.01 \mathrm{nS} / \mathrm{pF}(n=31)$ in control neurons to $0.23 \pm 0.02 \mathrm{nS} / \mathrm{pF}(n=31)$ in CCD neurons (Student's $t$ test; $p<0.01)$.

\section{CCD does not change the voltage dependence of $I_{h}$ activation}

The activation curve of $I_{\mathrm{h}}$ current was estimated by measuring the tail current at $-120 \mathrm{mV}$ after application of prepulse potentials between -40 and $-120 \mathrm{mV}$ (Fig. 3A). Tail currents were normalized to the maximal current (obtained at a prepulse of $-120 \mathrm{mV}$ ). The activation curve for each neuron was fitted with a Boltzmann equation of the following form: $I_{\text {tail }} / I_{\text {tail }(\max )}=\left(1+e^{\left(\left(V_{\mathrm{m}}-V_{0.5}\right) / k\right)}\right)^{-1}$, where $V_{\mathrm{m}}$ is the membrane potential of the prepulse, $V_{0.5}$ is the membrane potential at which $I_{\mathrm{h}}$ conductance is half-activated, $k$ is a slope factor, $I_{\text {tail }}$ is the peak amplitude of the tail current recorded immediately after the prepulse, and $I_{\text {tail(max) }}$ is the tail current recorded after the maximal prepulse of $-120 \mathrm{mV}$. $V_{0.5}$ was measured from the activation curve (Fig. $3 B$ ), and values were not significantly different for control $(-74.2 \pm 4.6 \mathrm{mV} ; n=34)$ vs CCD $(-73.5 \pm$ $4.6 \mathrm{mV} ; n=51$; Student's $t$ test; $p=0.52$ ) neurons. The slope factors for each group were not significantly different $(6.2 \pm 1.8 \mathrm{mV}$ for control and $6.6 \pm 1.4 \mathrm{mV}$ for CCD neurons; Student's $t$ test; $p=$ $0.19)$.

\section{CCD increases the rate of activation of $I_{h}$ current}

$I_{\mathrm{h}}$ was activated by a series of hyperpolarizing test potentials of -60 to $-120 \mathrm{mV}$ from a holding potential of $-50 \mathrm{mV}$ (Fig. $4 \mathrm{~A}$, inset). Test potentials of shorter duration were used at more hyperpolarized potentials to avoid damaging the cell membrane. The time course of activation of $I_{\mathrm{h}}$ was fitted to first- and secondorder exponential functions. On the basis of the criterion of Horn (1987), the current traces were not well described by a single exponential function but rather by the sum of two exponential functions (Fig. 4A). The equation was of the following form: $I_{\mathrm{h}}(t)=A_{f} e^{(-t / \tau f)}+A_{s} e^{(-t / \tau s)}$, where $I_{\mathrm{h}}(t)$ is the amplitude of the current at time $t$, and $A_{f}$ and $A_{s}$ are the amplitude coefficients of the fast $\left(\tau_{f}\right)$ and slow $\left(\tau_{s}\right)$ time constants, respectively. The relative proportion of the total current in the slow and fast components did not differ significantly across activation potential or between control and CCD neurons (Fig. 4B) (two-way RMANOVA, $p>$ $0.05)$. In general, $I_{\mathrm{h}}$ current activated faster at more hyperpolarized potentials (Fig. 4A). For example, from -80 to $-120 \mathrm{mV}$, the mean $\tau_{f}$ decreased from 302 to $68 \mathrm{msec}$ in control neurons and from 175 to $52 \mathrm{msec}$ in CCD neurons (Fig. $4 C$ ). $\tau_{f}$ was significantly faster in CCD than in control neurons for voltages of -70 to $-90 \mathrm{mV}$ ( $n=17$ for control; $n=21$ for CCD; two-way RMANOVA; Tukey's HSD; $p<0.05$ ) (Fig. $4 C$ ). From -80 to $-120 \mathrm{mV}$, the mean $\tau_{s}$ decreased from 1134 to $636 \mathrm{msec}$ in control neurons and from 925 to $445 \mathrm{msec}$ in CCD neurons. $\tau_{s}$ was significantly faster in CCD than in control neurons for voltages of

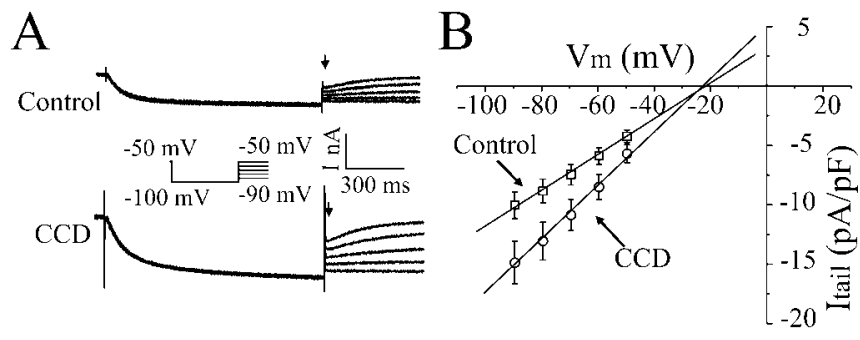

Figure 2. Effects of $C C D$ on the conductance and reversal potential of $I_{\mathrm{h}}$ current. $A$, In a control (top) and a CCD (bottom) neuron, $I_{\mathrm{h}}$ was fully activated by a hyperpolarizing prepulse to $-100 \mathrm{mV}$ for $1 \mathrm{sec}$, followed by a depolarization to test potentials of -90 to $-50 \mathrm{mV}$ (inset). Tail currents were measured at the start of the test potentials (arrows). B, Leak-subtracted tail current versus test potential. Squares and circles represent control and CCD neurons, respectively. The solid lines are the linear regressions fitted to the data points for each group. The slopes of the linear regressions were 0.15 and $0.23 \mathrm{nS} / \mathrm{pF}$ for control and CCD, respectively. The reversal potentials were -21 and $-23 \mathrm{mV}$ for control and CCD, respectively.
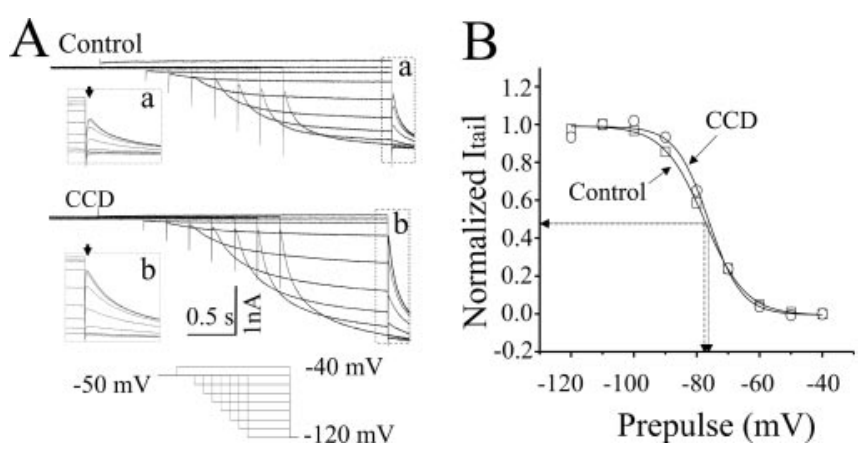

Figure 3. Effects of $C C D$ on the voltage dependence of $I_{\mathrm{h}}$ activation. $A, I_{\mathrm{h}}$ was activated from a holding potential of $-50 \mathrm{mV}$ to prepulse potentials ranging from -40 to $-120 \mathrm{mV}$, followed by a step to a test potential of $-120 \mathrm{mV}$ (voltage protocol as shown at bottom). The magnitude of the tail current at the start of the test potential was used as an index of $I_{\mathrm{h}}$ activation (arrows in insets $a$ and $b$ ). The tail currents of a control (top) and a CCD (middle) neuron are shown. $B$, Activation curves obtained by fitting the data of a control (squares) and a CCD (circles) neuron (as shown in $A$, top and middle, respectively) with single Boltzmann functions. The fitting yielded midpoint potentials, $V_{0.5}$, and slope factors, $k$, of -76.2 and $5.3 \mathrm{mV}$ for control and -77.4 and $6.5 \mathrm{mV}$ for CCD neurons, respectively.

-90 to $-110 \mathrm{mV}$ ( $n=17$ for control; $n=21$ for CCD; two-way RMANOVA; Tukey's HSD; $p<0.05$ ) (Fig. 4D).

The deactivation kinetics were estimated using an envelope technique described by Mayer and Westbrook (1983). Neurons were subjected to a prepulse potential of $-110 \mathrm{mV}$ to fully activate $I_{\mathrm{h}}$, followed by a repolarization (deactivation) to a test potential of varying duration, followed, in turn, by a return to -90 $\mathrm{mV}$ (Fig. 5A). The magnitude of deactivation was calculated by measuring the amount of $I_{\mathrm{h}}$ remaining after the test potential. The measurements were obtained at test potentials of $-60,-50$, -40 , and $-30 \mathrm{mV}$ (Fig. $5 B$ ).

Because the data were not equally spaced in this experiment, the Levenberg-Marquardt method (Clampfit; Axon Instruments) was used for curve fitting. A single exponential equation fitted the data best as determined using a model comparison procedure (pClampfit; Axon Instruments) (Fig. $5 \mathrm{C}$ ). The deactivation of $I_{\mathrm{h}}$ became faster when membrane potentials were more depolarized. For example, in a control neuron, the deactivation time constants were $512.3,342.6,228.2$, and $141.4 \mathrm{msec}$ at potentials of $-60,-50,-40$, and $-30 \mathrm{mV}$, respectively (Fig. $5 C$ ). The deactivation time constants of $I_{\mathrm{h}}$ were plotted as a function of test potential for control and CCD neurons (Fig. 5D). The functions were well described by $\tau(\mathrm{msec})=15.8+9.9 \exp \left(-V_{\mathrm{m}} / 17\right)$ for 
control and $\tau$ (msec) $=15.6+12.1$ $\exp \left(-V_{\mathrm{m}} / 18\right)$ for CCD neurons. The deactivation time constants of $I_{\mathrm{h}}$ from both groups showed a clear voltage dependence, with an $e$-fold decrease of $17 \mathrm{mV}$ (control) or $18 \mathrm{mV}$ (CCD) depolarization (Fig. 5D). However, at each depolarizing voltage, the deactivation time constants were not significantly different between the two groups ( $n=19$ for control and $n=23$ for CCD neurons; two-way RMANOVA; $p>0.05$ ) (Fig. 5D). For example, mean time constants were $73.4 \pm$ 7.0 (control) and $77.0 \pm 6.2$ (CCD) $\mathrm{msec}$ at $-30 \mathrm{mV}$.

\section{$I_{h}$ does not contribute to the resting membrane potentials of control or CCD neurons}

To determine whether $I_{\mathrm{h}}$ contributes to resting membrane potential, neurons were recorded in the current-clamp mode with no holding current. A periodic hyperpolarizing pulse $(-0.3$ to $-0.7 \mathrm{nA}, 200$ msec) was applied every $3 \mathrm{sec}$ for the measurement of membrane resistance and to demonstrate the presence of "depolarization sag," the latter an index of $I_{\mathrm{h}}$ current. Under control conditions, there was no significant difference between the mean resting potentials of control and CCD neurons $(-58 \pm 4 \mathrm{mV}(n=24)$ and $-57 \pm 6 \mathrm{mV}(n=17)$, respectively; Student's $t$ test; $p=0.42)$. Application of $I_{\mathrm{h}}$ channel blockers Cs ${ }^{+}(1 \mathrm{mM})$ and ZD7288 (15 $\mu \mathrm{M}$ ) eliminated the depolarization sag (Fig. 6A, B, bottom) but did not change resting membrane potential (Fig. $6 A, B, t o p$ ).

\section{Discussion}

The major finding of this study is that CCD increased the density of $I_{\mathrm{h}}$ current in DRG somata because of an increase in $I_{\mathrm{h}}$ conductance and also increased the rate of activation of $I_{\mathrm{h}}$ current.

\section{Characterization of $I_{\mathrm{h}}$ in DRG neurons}

The kinetics of activation of $I_{\mathrm{h}}$ observed in this study are generally consistent with that described previously by other laboratories. We found that the activation kinetics of $I_{\mathrm{h}}$ are voltage dependent and are best described by a double exponential in rat DRG neurons. The $\tau_{f}$ and $\tau_{s}$ were similar to values reported for neonatal rat DRG neurons (Wang et al., 1997). The complicated kinetics of activation may reflect the presence of multiple isoforms of the $I_{\mathrm{h}}$ channel. Four members of a gene family encoding mammalian $\mathrm{HCN}$ channels (HCN1-HCN4) have been cloned in recent years. When expressed in HEK 293 cells, recombinant HCN1-HCN4 channels demonstrate unique activation kinetics, i.e., with the fastest time constant for HCN1 and gradually slower time constants for HCN2-HCN4 (Moosmang et al., 2001). The two distinct time constants obtained in our preparation may indicate that two kinds of homomeric channels exist in DRG neurons, as has been proposed for sinoatrial node cells (Moosmang et al., 2001). This is consistent with the observation of Chaplan et al. (2001) that both HCN1 and HCN3 isoforms are present in rat DRG.

The parameters of steady-state activation of $I_{\mathrm{h}}$ observed in our recordings are consistent with those reported previously for DRG neurons in rodents. We obtained a half-activation voltage of -74 $\mathrm{mV}$, consistent with the value $(-73 \mathrm{mV})$ obtained previously for medium-sized rat DRG neurons (Cardenas et al., 1999). Our $V_{0.5}$ value is more positive than those of neonatal rat DRG neurons (Wang et al., 1997), possibly because of the absence of ATP in their recording pipette. ATP has been shown to cause a depolarizing shift of $V_{0.5}$ in mouse DRG neurons (Raes et al., 1997). The $I_{\mathrm{h}}$ conductance of $0.13 \mathrm{nS} / \mathrm{pF}$ at $-100 \mathrm{mV}$ is within range of values obtained in a variety of neuronal types (Pape, 1996), and our reversal potential value of $-21 \mathrm{mV}$ is virtually identical to those reported previously for DRG neurons in rodents (Raes et al., 1997; Wang et al., 1997).

\section{Effect of CCD on $I_{h}$}

A major finding of our study is that the magnitude of $I_{\mathrm{h}}$ increased after CCD. The immediate cause of the increase in $I_{\mathrm{h}}$ may be complicated, because this model is presumably associated with ischemia-hypoxia and inflammation. A local inflammation and acidosis could recruit mast cells and macrophages that release inflammatory mediators, such as 5-HT, prostaglandin $\mathrm{E}_{2}$, ATP, NGF, and cytokines (Millan, 1999). These mediators can activate cellular mechanisms that alter the expression of HCN channels, change the intrinsic properties of HCN channels, and/or increase the amount of cAMP binding to the $I_{\mathrm{h}}$ channel or enhancing the phosphorylation processes. Results using other models of neuropathic pain have had inconsistent effects on $I_{\mathrm{h}}$. After transection of the sciatic nerve, $I_{\mathrm{h}}$ was found to decrease in one study (Abdulla and Smith, 2001), but, in another study, transection of the spinal nerve caused $I_{\mathrm{h}}$ to increase (Chaplan et al., 2001). A reconciliation among these models and observations is not immediately obvious. 



A



B

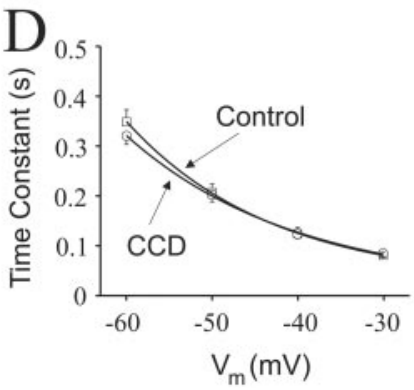

Figure 5. Effects of $C C D$ on the deactivation of $I_{\mathrm{h}}$ current. $A$, Current response (top) of a control neuron evoked by a triple-pulse voltage protocol (bottom). A hyperpolarizing potential of $-110 \mathrm{mV}$ was followed by different durations of a depolarization to $-30 \mathrm{mV}$ to deactivate $I_{\mathrm{h}}$ current and a hyperpolarization to $-90 \mathrm{mV}$ to reactivate $I_{\mathrm{h}}$ (the number of traces was reduced for clarity). The amplitude of $I_{h}$ current (shown as an example in the right trace) activated by the third pulse was used to calculate the deactivation time constant. $B$, Current responses of a control cell (same cell as in $A$ ) to the triple protocol but with deactivating potentials of -30 , $-40,-50$, and $-60 \mathrm{mV}(a-d$, respectively). Current traces were truncated at the end of $b-d$ to keep the same time scale as that in $a$. The number of data points in each current trace in both $A$ and $B$ were reduced to $1 / 10$. C, The effect of potential on the time course of $I_{h}$ current deactivation. Data points are fit by a single exponential. $D$, Mean time constant of deactivation of $I_{\mathrm{h}}$ current versus membrane potential for control and $C C D$ neurons (squares and circles, respectively). The single exponential functions fitted to the data points for each group are not significantly different for $C \mathrm{CD}$ and control neurons.

There are several possible explanations for the increase in magnitude of $I_{\mathrm{h}}$ observed in this study. (1) There may be a change in $\mathrm{HCN}$ isoform, as occurs for sodium currents after peripheral axotomy (Dib-Hajj et al., 1999; Ishikawa et al., 1999; Kim et al., 2001). However, we believe this to be unlikely, because CCD did not alter the ratio of $A_{f} f\left(A_{f}+A_{\mathrm{s}}\right)$. Thus, if there are two homomers of the HCN channel, neither of them became dominant after CCD. (2) A $\beta$-subunit for the HCN channel family may exist (Yu et al., 2001), and changes in its expression could modify the $I_{\mathrm{h}}$ current properties, as has been observed in $\mathrm{Na}^{+}, \mathrm{Ca}^{2+}$, and $\mathrm{K}^{+}$ channels (Isom et al., 1994). (3) Intracellular messengers, particularly cAMP, may have modified $I_{\mathrm{h}}$. HCN channels have a cyclic binding domain located in the $\mathrm{C}$ terminal (Wainger et al., 2001) and PKA consensus phosphorylation sites (Santoro et al., 1998; Gauss and Seifert, 2000; Vargas and Lucero, 2002). Electrophysiological studies have shown that cAMP enhances $I_{\mathrm{h}}$ by altering the voltage dependence of activation (Ingram and Williams, 1996; Cardenas et al., 1999). However, we did not observe a change in activation properties after CCD in our experiments. These possibilities provide several possible paths for the pursuit of additional experiments.

\section{Functional implications of increased $I_{\mathrm{h}}$ in CCD neurons}

CCD increases the excitability of DRG neurons, as indicated by an increased incidence of spontaneous activity and subthreshold oscillations in membrane potential and lowered current and action potential thresholds (Hu and Xing, 1998; Song et al., 1999; Zhang et al., 1999; Xing et al., 2001). The increased $I_{\mathrm{h}}$ current conductance we observed may account for the higher incidence



Figure 6. The effects of $I_{h}$ on the resting membrane potential. Current-clamp recordings of the resting membrane potential $\left(V_{\text {rest }}\right)$ of a control $(A)$ and a $C C D(B)$ neuron. The respective initial values of $V_{\text {rest }}$ for the control and $C C D$ neurons were -53 and $-56 \mathrm{mV}$. Current pulses of $-0.6 \mathrm{nA}, 200 \mathrm{msec}$, were injected into each cell every 3 sec to elicit a hyperpolarization and sag in voltage response. The horizontal bars indicate the durations of application of the $I_{h}$ blockers $\mathrm{Cs}^{+}(1 \mathrm{~mm})$ and ZD7288 $(15 \mu \mathrm{M})$. A, B, Top trace, Voltage responses to the current injection; bottom trace, enlarged voltage traces to show the reduction in sag produced by the blocker. Note that, in both control and CCD neurons, both $1 \mathrm{~mm} \mathrm{Cs}{ }^{+}$and $15 \mu \mathrm{m}$ ZD7288 did not alter resting potential but had similar effects in abolishing the sag.

of spontaneous activity and contribute to neuropathic pain. The latter is supported by the observation that ZD7288 blocked neuropathic pain caused by spinal nerve ligation (Chaplan et al., 2001).

In CCD neurons, a repolarization of an action potential will produce a greater depolarization because of increased $I_{\mathrm{h}}$ and thus have a greater chance of evoking another action potential, possibly enhancing the occurrence of repetitive discharge either autonomously or in response to excitatory stimuli. For example, in rat DRG neurons, an increase of $I_{\mathrm{h}}$ by $5-\mathrm{HT}$ increased the number of anode break discharges. A reduction of $I_{\mathrm{h}}$ by clonidine decreased the rate of evoked multispike intervals (Yagi and Sumino, 1998; Cardenas et al., 1999). In hippocampal neurons, inhibition of $I_{\mathrm{h}}$ by its blocker ZD7288 reduced the frequency of spontaneous activity and blocked the evoked multispike discharge (Maccaferri and McBain, 1996; Gasparini and DiFrancesco, 1997). An increase of $I_{\mathrm{h}}$ mediated through the $\beta$-adrenergic receptor by the $\beta$-agonist isoproterenol (ISP) increased the frequency of spontaneous spikes recorded from rat cerebellar basket cells, whereas ZD7288 decreased the spike frequency and abolished the ISP-induced increase in spike discharges (Saitow and Konishi, 2000).

In conclusion, the increase in $I_{\mathrm{h}}$ current density that we observed after CCD could contribute to an increased incidence of spontaneous activity and subthreshold oscillations in membrane potential and thus to the genesis of neuropathic pain. 


\section{References}

Abdulla FA, Smith PA (2001) Axotomy-and autotomy-induced changes in $\mathrm{Ca}^{2+}$ and $\mathrm{K}^{+}$channel currents of rat dorsal root ganglion neurons. J Neurophysiol 85:644-658.

BoSmith RE, Briggs I, Sturgess NC (1993) Inhibitory actions of ZENECA ZD7288 on whole-cell hyperpolarization activated inward current (If) in guinea-pig dissociated sinoatrial node cells. Br J Pharmacol 110:343-349.

Cardenas CG, Mar LP, Vysokanov AV, Arnold PB, Cardenas LM, Surmeier DJ, Scroggs RS (1999) Serotonergic modulation of hyperpolarizationactivated current in acutely isolated rat dorsal root ganglion neurons. J Physiol (Lond) 518:507-523.

Chaplan SR, Guo HQ, Lee DH, Butler MP, Velumian A, Dubin AE (2001) Markedly increased DRG $I_{\mathrm{h}}$ and HCN mRNA accompany neuropathic pain in the rat. Soc Neurosci Abstr 27:54.11.

Dib-Hajj SD, Fjell J, Cummins TR, Zheng Z, Fried K, LaMotte R, Black JA, Waxman SG (1999) Plasticity of sodium channel expression in DRG neurons in the chronic constriction injury model of neuropathic pain. Pain 83:591-600.

DiFrancesco D (1993) Pacemaker mechanisms in cardiac tissue. Annu Rev Physiol 55:455-472.

Gasparini S, DiFrancesco D (1997) Action of the hyperpolarizationactivated current $\left(I_{\mathrm{h}}\right)$ blocker ZD 7288 in hippocampal CA1 neurons. Pflügers Arch 435:99-106.

Gauss R, Seifert R (2000) Pacemaker oscillations in heart and brain: a key role for hyperpolarization-activated cation channels. Chronobiol Int $17: 453-469$.

Horn R (1987) Statistical methods for model discrimination: applications to gating kinetics and permeation of the acetylcholine receptor channel. Biophys J 51:255-263.

Hu SJ, Xing JL (1998) An experimental model for chronic compression of dorsal root ganglion produced by intervertebral foramen stenosis in the rat. Pain 77:15-23.

Ingram SL, Williams JT (1996) Modulation of the hyperpolarizationactivated current $\left(I_{\mathrm{h}}\right)$ by cyclic nucleotides in guinea-pig primary afferent neurons. J Physiol (Lond) 492:97-106.

Ishikawa K, Tanaka M, Black JA, Waxman SG (1999) Changes in expression of voltage-gated potassium channels in dorsal root ganglion neurons following axotomy. Muscle Nerve 22:502-507.

Isom LL, De Jongh KS, Catterall WA (1994) Auxiliary subunits of voltagegated ion channels. Neuron 12:1183-1194.

Kim DS, Yoon CH, Lee SJ, Park SY, Yoo HJ, Cho HJ (2001) Changes in voltage-gated calcium channel alpha(1) gene expression in rat dorsal root ganglia following peripheral nerve injury. Brain Res Mol Brain Res 96:151-156.

Liu CN, Devor M, Waxman SG, Kocsis JD (2002) Subthreshold oscillations induced by spinal nerve injury in dissociated muscle and cutaneous afferents of mouse DRG. J Neurophysiol 87:2009-2017.

Luthi A, McCormick DA (1998) H-current: properties of a neuronal and network pacemaker. Neuron 21:9-12.

Maccaferri G, McBain CJ (1996) The hyperpolarization-activated current $\left(I_{\mathrm{h}}\right)$ and its contribution to pacemaker activity in rat CA1 hippocampal stratum oriens-alveus interneurones. J Physiol (Lond) 497:119-130.

Mayer ML, Westbrook GL (1983) A voltage-clamp analysis of inward (anomalous) rectification in mouse spinal sensory ganglion neurones. J Physiol (Lond) 340:19-45.

Millan MJ (1999) The induction of pain: an integrative review. Prog Neurobiol 57:1-164.
Moosmang S, Stieber J, Zong X, Biel M, Hofmann F, Ludwig A (2001) Cellular expression and functional characterization of four hyperpolarization-activated pacemaker channels in cardiac and neuronal tissues. Eur J Biochem 268:1646-1652.

Oyelese AA, Kocsis JD (1996) GABA $_{\mathrm{A}}$-receptor-mediated conductance and action potential waveform in cutaneous and muscle afferent neurons of the adult rat: differential expression and response to nerve injury. J Neurophysiol 76:2383-2392.

Pape HC (1996) Queer current and pacemaker: the hyperpolarizationactivated cation current in neurons. Annu Rev Physiol 58:299-327.

Raes A, Wang Z, van den Berg RJ, Goethals M, Van de Vijver G, van Bogaert PP (1997) Effect of cAMP and ATP on the hyperpolarization-activated current in mouse dorsal root ganglion neurons. Pflügers Arch 434:543-550.

Rizzo MA, Kocsis JD, Waxman SG (1995) Selective loss of slow and enhancement of fast $\mathrm{Na}^{+}$currents in cutaneous afferent dorsal root ganglion neurones following axotomy. Neurobiol Dis 2:87-96.

Saitow F, Konishi S (2000) Excitability increase induced by beta-adrenergic receptor-mediated activation of hyperpolarization-activated cation channels in rat cerebellar basket cells. J Neurophysiol 84:2026-2034.

Santoro B, Liu DT, Yao H, Bartsch D, Kandel ER, Siegelbaum SA, Tibbs GR (1998) Identification of a gene encoding a hyperpolarization-activated pacemaker channel of brain. Cell 93:717-729.

Satoh TO, Yamada M (2000) A bradycardiac agent ZD7288 blocks the hyperpolarization-activated current $(\mathrm{I}(\mathrm{h}))$ in retinal rod photoreceptors. Neuropharmacology 39:1284-1291.

Scroggs RS, Todorovic SM, Anderson EG, Fox AP (1994) Variation in IH, IIR, and ILEAK between acutely isolated adult rat dorsal root ganglion neurons of different size. J Neurophysiol 71:271-279.

Song XJ, Hu SJ, Greenquist KW, Zhang JM, LaMotte RH (1999) Mechanical and thermal hyperalgesia and ectopic neuronal discharge after chronic compression of dorsal root ganglia. J Neurophysiol 82:3347-3358.

Vargas G, Lucero MT (2002) Modulation by PKA of the hyperpolarizationactivated current $\left(I_{\mathrm{h}}\right)$ in cultured rat olfactory receptor neurons. J Membr Biol 188:115-125.

Villiere V, McLachlan EM (1996) Electrophysiological properties of neurons in intact rat dorsal root ganglia classified by conduction velocity and action potential duration. J Neurophysiol 76:1924-1941.

Wainger BJ, DeGennaro M, Santoro B, Siegelbaum SA, Tibbs GR (2001) Molecular mechanism of cAMP modulation of HCN pacemaker channels. Nature 411:805-810.

Wang Z, Van Den Berg RJ, Ypey DL (1997) Hyperpolarization-activated currents in the growth cone and soma of neonatal rat dorsal root ganglion neurons in culture. J Neurophysiol 78:177-186.

Xing JL, Hu SJ, Long KP (2001) Subthreshold membrane potential oscillations of type A neurons in injured DRG. Brain Res 901:128-136.

Yagi J, Sumino R (1998) Inhibition of a hyperpolarization-activated current by clonidine in rat dorsal root ganglion neurons. J Neurophysiol 80:1094-1104.

Yu H, Wu J, Potapova I, Wymore RT, Holmes B, Zuckerman J, Pan Z, Wang H, Shi W, Robinson RB, El-Maghrabi MR, Benjamin W, Dixon J, McKinnon D, Cohen IS, Wymore R (2001) MinK-related peptide 1: a beta subunit for the $\mathrm{HCN}$ ion channel subunit family enhances expression and speeds activation. Circ Res 88:E84-E87.

Zhang JM, Song XJ, LaMotte RH (1999) Enhanced excitability of sensory neurons in rats with cutaneous hyperalgesia produced by chronic compression of the dorsal root ganglion. J Neurophysiol 82:3359-3366. 